\title{
Idiopathic bone cavity: clinical and radiological features of 90 retrospective cases and surgical treatment
}

\author{
Jihye Ryu, Inhye Nam, Sang-Hun Shin, Yong-Deok Kim, Jae-Yeol Lee \\ Department of Oral and Maxillofacial Surgery, School of Dentistry, Pusan National University, Yangsan, Korea
}

Abstract (J Korean Assoc Oral Maxillofac Surg 2021;47:360-364)

Objectives: The purpose of this study was to evaluate the clinical and radiographic characteristics of idiopathic bone cavity (IBC) to determine the effect of surgical intervention on the process of healing.

Materials and Methods: All cases diagnosed with IBC during the period of 2011 to 2020 at our Department of Oral and Maxillofacial Surgery were searched. Ninety cases were retrieved. The features evaluated were sex, age, contour of the lesion, number of teeth involved, site, history of trauma, and postoperative healing pattern. The significance of differences was assessed by Mann-Whitney U test and chi-square test.

Results: The female:male ratio showed no predilection toward either sex (0.9:0.8). The mean age of the collected sample was $22.05 \pm 14.38$ years, and the age ranged from 10 to 58 years. All cases presented in the mandible and showed well-circumscribed radiolucency. Margins were either scalloped or round in shape, and the size varied from one tooth to six teeth involvement. Seventy cases involved three or fewer roots. Three cases showed bilateral lesion. Four cases had a history of trauma at the area of the lesion. Fifty-one cases were followed for six months after surgery, and all showed increased bone density at the lesion.

Conclusion: There is no definitive radiological or clinical feature of IBC. Considering the diversity of clinical and radiological features, such a diagnosis relies primarily on surgical findings of an empty bone cavity with no epithelial lining. Our data suggest that surgical intervention be the first choice of treatment as opposed to observation.

Key words: Solitary cysts, Bone cysts, Jaw cysts, Treatment

[paper submitted 2021. 7. 13 / accepted 2021. 8. 17]

\section{Introduction}

Idiopathic bone cavity (IBC), also known as simple or traumatic bone cyst, is defined by the World Health Organization as a non-neoplastic intraosseous pseudocyst devoid of epithelial lining ${ }^{1}$. With its lack of cystic lining, histopathological confirmation of IBC can be achieved in some cases where fibrous tissues are present, but is difficult since collecting tissue samples within an empty cavity often is not possible ${ }^{1,2}$. IBC is often asymptomatic, occurs in young patients in their

\footnotetext{
Jae-Yeol Lee

Department of Oral and Maxillofacial Surgery, School of Dentistry, Pusan National University, 49 Busandaehak-ro, Mulgeum-eup, Yangsan 50612, Korea

TEL: $+82-55-360-5100$

E-mail:omsljy@pusan.ac.kr

ORCID: https://orcid.org/0000-0003-0678-2499
}

(c) This is an open-access article distributed under the terms of the Creative Commons Attribution Non-Commercial License (http://creativecommons.org/ licenses/by-nc/4.0/), which permits unrestricted non-commercial use, distribution, and reproduction in any medium, provided the original work is properly cited.

Copyright (C) 2021 The Korean Association of Oral and Maxillofacial Surgeons. second to third decade of life $^{2}$, and is a solitary lesion ${ }^{3}$, in the posterior site of the mandible, and shows no association with $\operatorname{sex}^{4}$. Despite its clear description, the pathogenesis of idiopathic bone cavity remains unclear ${ }^{3,5}$. Thus, it is uncertain whether surgical intervention is necessary ${ }^{3}$ or if a surgically untreated lesion could yield spontaneous resolution. Few studies have reported cases of spontaneous resolution of surgically untreated IBC, but a longer follow-up period was needed to observe complete resolution ${ }^{5}$. Discacciati et al. ${ }^{6}$ suggest differentiation from a lesion with other maxillofacial cystic or neoplastic pathologies can be based on clinical and radiographical findings, but surgical exploration can serve as a definitive diagnostic tool. Its many names reflect the diverse clinical and radiological presentation of idiopathic bone cavity, and more extensive studies are needed to increase understanding of the lesion. The purpose of this study was to evaluate the clinical and radiographic characteristics of idiopathic bone cavity and the necessity of surgical intervention. 

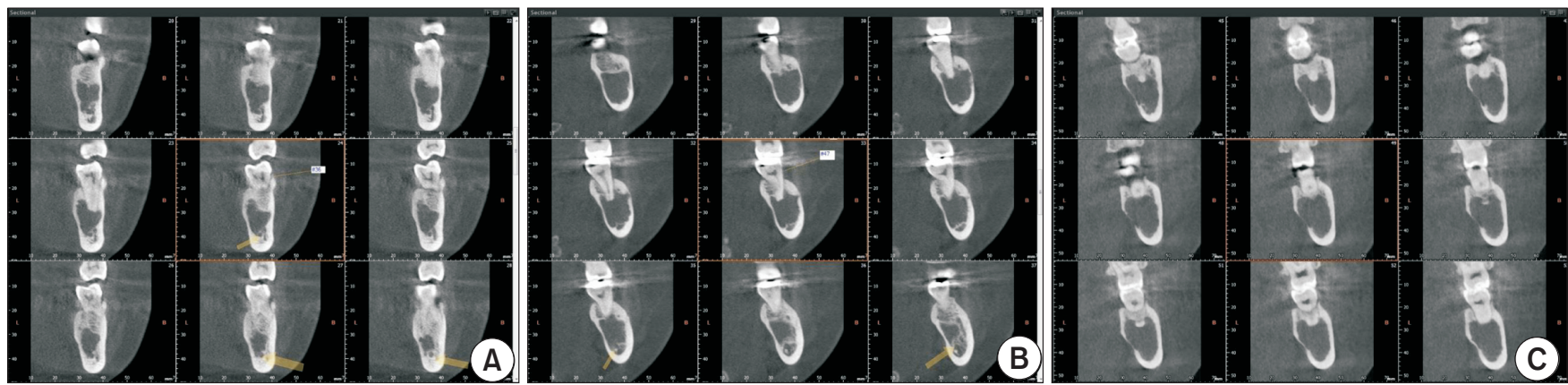

Fig. 1. Cone-beam computed tomography of different degrees of bone thinning pattern. A. Mild cortical bone thinning. B. Moderate cortical bone thinning. C. Severe cortical bone thinning.

Jihye Ryu et al: Idiopathic bone cavity: clinical and radiological features of 90 retrospective cases and surgical treatment. J Korean Assoc Oral Maxillofac Surg 2021
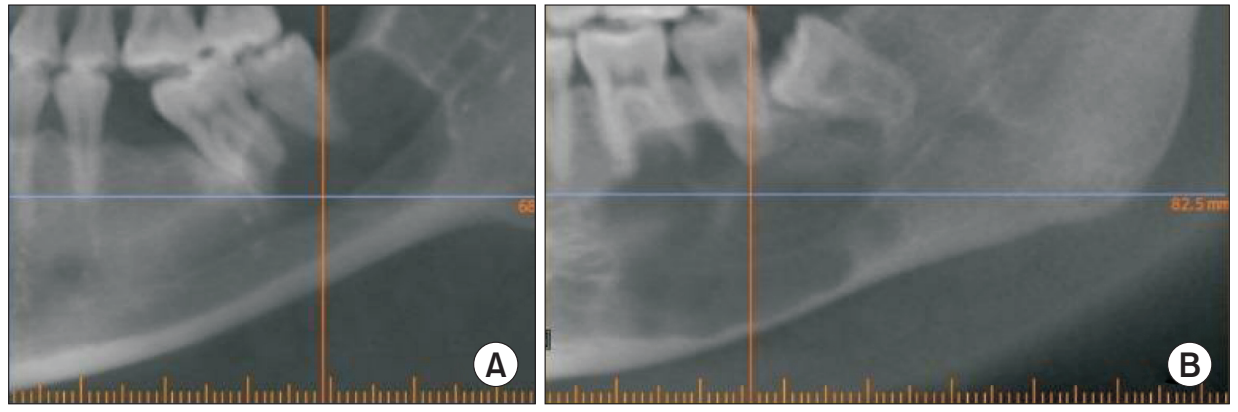

Fig. 2. Panoramic view of idiopathic bone cavity contour. A. Rounded contour. B. Scalloped contour.

Jihye Ryu et al: Idiopathic bone cavity: clinical and radiological features of 90 retrospective cases and surgical treatment. J Korean Assoc Oral Maxillofac Surg 2021

\section{Materials and Methods}

\section{Case selection}

A search of all cases that were first diagnosed as idiopathic bone cavity among patients from 2011 to 2020, at the Department of Oral and Maxillofacial Surgery, Pusan National University Hospital (Yangsan, Korea) was conducted. Inclusion criteria for these cases were availability of diagnostic X-rays; clinical, radiographic, and surgical description of the lesion; and histopathology. The follow-up period differed by case so postoperative comparison of lesions was based on the cases that had a greater than six-month follow-up period and radiographic images.

Any case that was diagnosed as idiopathic bone cavity but did not undergo surgical treatment was not included in the study. Lesions that were misdiagnosed and cases where patients had systemic disease that might interfere with healing also were excluded.

\section{Variables}

Clinical parameters evaluated were sex, age, clinical symptoms, pulp vitality, bone expansion (Fig. 1), lesion contour (Fig. 2), number of teeth involved, location of lesion, history of trauma, and postoperative healing pattern.

\section{Statistical analysis}

The Mann-Whitney U test and chi-square test were performed using IBM SPSS Statistics software (ver. 25.0; IBM, Armonk, NY, USA). $P<0.05$ was considered statistically significant.

\section{Results}

A total of 90 cases was included in this study.(Table 1) All cases had preoperative cone-beam computed tomography data and panoramic radiographs. The mean age at presentation of IBC was $22.05 \pm 14.38$ years, which ranged from 10 to 58 years. There was no predilection between the two sexes. A single case was observed in the maxilla, with the remaining cases in the mandibular region. History of trauma associated with the lesion was acquired at the first visit and documented, but most cases showed no specific traumatic incidence. The legion size was measured in two categories with respect to the adjacent teeth involved, either of equal or smaller size than three teeth or greater than three teeth. The majority of cases (65 cases) involved three or fewer teeth. Patients younger than 20 years showed more lesions (21 cases) 
Table 1. Clinical variables of idiopathic bone cavity and statistical data $(n=90)$

\begin{tabular}{|c|c|c|}
\hline Variable & Value & $P$-value \\
\hline Age (yr) & $22.05 \pm 14.38(10-58)$ & - \\
\hline Sex & & 0.610 \\
\hline Male & 40 & \\
\hline Female & 50 & \\
\hline \multicolumn{3}{|l|}{ Jaw } \\
\hline Maxilla & 1 & $<0.001 *$ \\
\hline Mandible & 89 & \\
\hline \multicolumn{3}{|l|}{ Trauma } \\
\hline Yes & 4 & 0.803 \\
\hline No & 9 & \\
\hline Unknown & 77 & \\
\hline \multicolumn{3}{|l|}{ Symptomatic } \\
\hline Yes & 17 & 0.656 \\
\hline No & 72 & \\
\hline Unknown & 1 & \\
\hline \multicolumn{3}{|l|}{ Pulp vitality } \\
\hline Vital & 54 & $0.004 *$ \\
\hline Non-vital & 12 & \\
\hline Vital+Non-vital & 4 & \\
\hline Unknown & 20 & \\
\hline \multicolumn{3}{|l|}{ Cortical bone thinning } \\
\hline None & 17 & \\
\hline Mild & 51 & 0.405 \\
\hline Moderate & 18 & \\
\hline Severe & 4 & \\
\hline \multicolumn{3}{|l|}{ Contour } \\
\hline Scalloped & 45 & 0.558 \\
\hline Round & 45 & \\
\hline \multicolumn{3}{|l|}{ Size } \\
\hline $\begin{array}{l}\text { Equal to or less than three teeth } \\
\text { involved }\end{array}$ & 70 & 0.735 \\
\hline Greater than three teeth involved & 20 & \\
\hline \multicolumn{3}{|l|}{ Location } \\
\hline Anterior & 33 & 0.922 \\
\hline Posterior & 57 & \\
\hline
\end{tabular}

$* P<0.05$.

Values are presented as mean \pm standard deviation (range) or number only.

Jihye Ryu et al: Idiopathic bone cavity: clinical and radiological features of 90 retrospective cases and surgical treatment. J Korean Assoc Oral Maxillofac Surg 2021

associated with a larger size than did the older (four cases) group $(P<0.05)$.(Table 2$)$ All asymptomatic IBCs were discovered incidentally during routine check-ups. However, 17 cases showed some clinical symptoms such as pain, swelling, idiopathic discomfort, or paresthesia. Involved teeth showed more frequent vitality than non-vitality. Cortical bone expansion was not found in 17 cases, and mild thinning of the cortex was seen in 51 cases (56.7\%). Radiographic presentation of IBCs was evaluated as either scalloped or round in shape, and the proportions were equal (1:1). Radiographic examination over six months after surgical curettage or exploration showed reduction in size and evidence of increased bone density.(Fig. 3) Increased bone density of the lesion in 51 cases was observed during the six-month follow-up period, while 39 patients were lost postoperatively.
Table 2. Comparative analysis of distribution by lesion size and age $(n=90)$

\begin{tabular}{|c|c|c|c|}
\hline & \multicolumn{2}{|c|}{$\begin{array}{l}\text { Size less or greater than } \\
\text { three teeth involved }\end{array}$} & \multirow{2}{*}{$P$-value } \\
\hline & Less $(n=65)$ & Greater $(n=25)$ & \\
\hline $\begin{array}{l}\leq 20 \mathrm{yr}(\mathrm{n}=62) \\
>20 \mathrm{yr}(\mathrm{n}=28)\end{array}$ & $\begin{array}{l}41(45.6) \\
24(26.7)\end{array}$ & $\begin{array}{c}21(23.3) \\
4(0.4)\end{array}$ & $0.038^{*}$ \\
\hline $\begin{array}{l}* P<0.05 \text {. } \\
P \text {-value by chi-squ } \\
\text { Values are present } \\
\text { Lesions with less } \\
\text { Lesions with great } \\
\text { Jihye Ryu et al: Idiopa } \\
\text { tive cases }\end{array}$ & $\begin{array}{l}\text { est. } \\
\text { number (\%). } \\
3 \text { teeth involv } \\
\text { an } 3 \text { teeth invo } \\
\text { ne cavity: clinical } \\
\text { ent. J Korean Ass }\end{array}$ & $\begin{array}{l}\text { considered as s } \\
\text { d considered as } \\
\text { tradiological feature }\end{array}$ & $\begin{array}{l}\text { gller lesion } \\
\text { ger lesion. } \\
90 \text { retrospec }\end{array}$ \\
\hline
\end{tabular}

\section{Discussion}

The pathogenesis of IBC remains theoretical despite its widely investigated clinical and radiological features. Among the major etiologic hypotheses, three have achieved some agreement and predominate: 1) abnormality of bone growth, 2) tumor degeneration, and 3) traumatism. The first two factors are based on clinical observation, and the third hypothesis considers the interaction between lesion pathogenesis and etiology. According to Harnet et al. ${ }^{7}$, traumatism is the most widely accepted theory, and it advocates vascular alterations caused by intramedullary hemorrhage after traumatic force on the lesion. Discacciati et al. ${ }^{6}$ also investigated these three factors, but they failed to observe significant results ${ }^{6}$.

The ambiguity of pathogenesis is partly due to various clinical and radiological features of IBCs. In many reported cases, presentation of IBCs varies by sex, size, preferential location, shape, recurrence, etc. Many studies have investigated clinical and radiological findings of IBCs in an effort to form differential diagnosis of the lesion from other benign intraosseous lesions, including odontogenic keratocyst, ameloblastoma, central giant cell lesions, lateral periodontal cysts, periapical cysts, and other odontogenic cysts ${ }^{4}$. Specifically, since radiological findings of IBCs mimic those of other cysts of the oral region, it is essential to investigate further to decide whether treatment intervention or follow-up observation is necessary. Some studies advocate conservative treatment as long as patients are free of symptoms since IBC is a benign lesion $^{8}$. A sexual predilection exists in some reviews and case reports ${ }^{6,9-12}$, while others including Rushton ${ }^{13}$ reveal no such predilection ${ }^{14-16}$. Our study, however, is in accordance with the latter case (male to female ratio as 0.9:1.0). In general, it is agreed that IBCs often are found incidentally in the second to third decades of life, with a location predominantly in the 

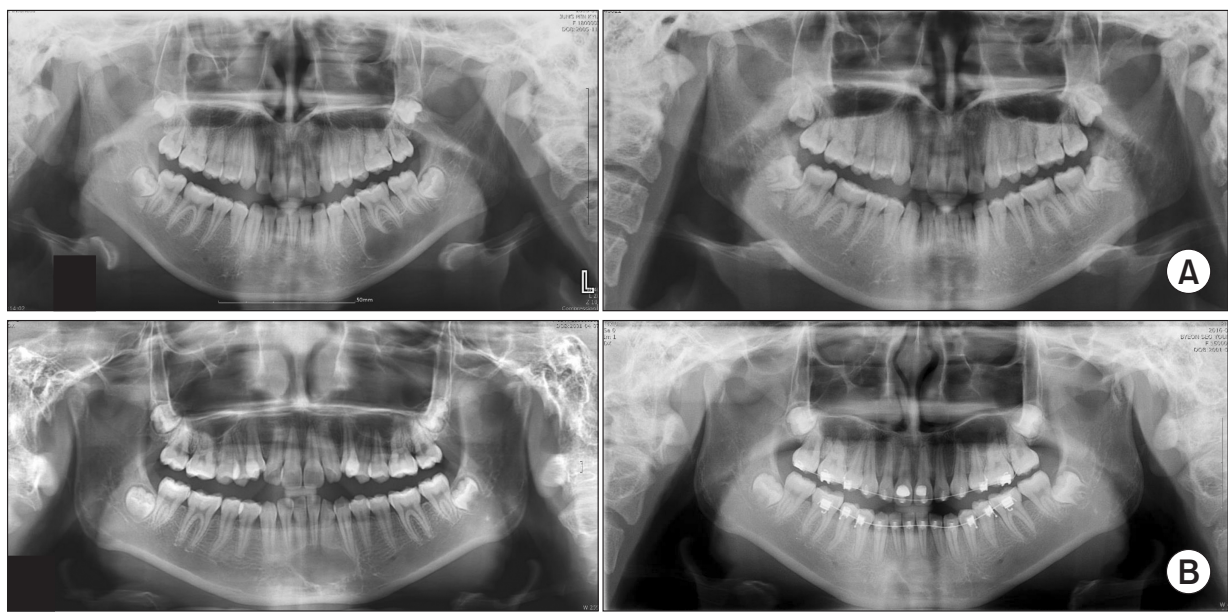

Fig. 3. Radiographic changes six months postoperatively. All cases underwent surgical curettage of the lesion. A. Left: Initial lesion on the left posterior of the mandible. Right: Postoperative lesion. B. Left: Initial lesion on the ante-
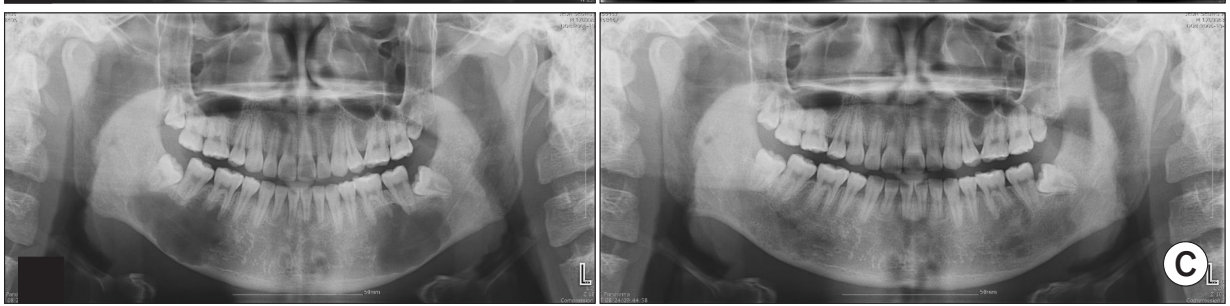
rior of the mandible. Right: Postoperative lesion. C. Left: Initial lesion on the right and left posterior mandible. Right: Postoperative lesion.

Jihye Ryu et al: Idiopathic bone cavity: clinical and radiological features of 90 retrospective cases and surgical treatment. J Korean Assoc Oral Maxillofac Surg 2021

mandible; this correlates with the data from our study ${ }^{10,12,17}$. You et al. ${ }^{10}$ reported the posterior mandible as the most common site, followed by the anterior region. Topographical distribution of all our cases, except one in the maxilla, was significantly higher in the posterior region of the mandible. In addition, 27 cases showed a lesion size greater than three teeth, and most of these patients were in their 20 s, which confirmed a significant size difference between the younger and older groups. There was no association between degree of cortical bone expansion and existing symptoms, and a mild degree of expansion was most common. Although solitary and unilocular radiolucency is most common in $\mathrm{IBCs}^{18}$, multiple IBCs were found in about $11 \%$ of cases ${ }^{11}$. Most of these lesions were treated surgically, and recurrence was rare ${ }^{11,19}$. Three cases showed bilateral lesion in the mandible and were diagnosed originally as keratocystic odontogenic tumor, after which surgical exploration confirmed the diagnosis as IBC. A characteristic IBC trait is scalloping of the lesion projection into the interdental or interradicular spaces ${ }^{2}$. Scalloping borderlines were seen in about $40 \%$ of IBCs ${ }^{1}$; however, our study showed equal proportions of scalloped and rounded lesion contours.

Considering the atypical presentation of IBCs and the diversity of theories put forward in the literature, the preferred treatment option is clear. Especially when routine check-ups reveal enlargement of a lesion, a surgical approach is logical ${ }^{8}$. Since final diagnosis and treatment can be performed simul- taneously in the same surgical procedure and as shown in our data, it is reasonable to consider surgical management of the lesion $^{20}$. Surgical curettage or exploration can stimulate bony growth by generating new blood flow into the site ${ }^{2,3,9}$.

Multiple treatment modalities exist to stimulate the healing process of the emptied bone cavity. Treatment options include no surgical intervention with expectation of spontaneous healing and a surgical approach that can involve exploration, curettage, fenestration, autologous bone marrows injection, cavity packing, etc. ${ }^{1,14}$. The effectiveness of these treatment modalities is not known ${ }^{14}$, and there is no consensus on treatment protocol. Our data, however, suggest that simple curettage of the lesion was sufficient to yield bone regeneration that is detectable through X-rays. One surgical procedure was needed to confirm the tentative diagnosis and rule out other oral pathologies; treatment was spontaneous healing.

\section{Conclusion}

Like the many synonyms for idiopathic bone cavity, its etiology remains unclear. The diagnosis of idiopathic bone cavity relies primarily on radiographic interpretation or the surgical finding of an empty bone cavity with a lack of epithelial lining. Our data suggest that surgical intervention be the first choice of treatment for stimulating healing of idiopathic bone cavity. 


\section{ORCID}

Jihye Ryu, https://orcid.org/0000-0001-5791-7387

Inhye Nam, https://orcid.org/0000-0002-2555-0469

Sang-Hun Shin, https://orcid.org/0000-0002-0467-6206

Yong-Deok Kim, https://orcid.org/0000-0002-5807-7487

Jae-Yeol Lee, https://orcid.org/0000-0003-0678-2499

\section{Authors' Contributions}

J.R. participated in data collection and wrote the manuscript. I.N., Y.D.K., and S.H.S. participated in the study design and performed the statistical analysis. J.Y.L. participated in the study design and coordination and helped to draft the manuscript. All authors read and approved the final manuscript.

\section{Ethics Approval and Consent to Participate}

The study was waived by the Institutional Review Board of Pusan National University Dental Hospital (IRB No. PNUDH-2021-030).

\section{Conflict of Interest}

No potential conflict of interest relevant to this article was reported.

\section{References}

1. Zhang W, Chen M, Yang C, Han Z, Wei W, Chai Y. Does idiopathic bone cavity involving mandibular condyle need surgical intervention of bone cavity filling? J Craniofac Surg 2017;28:e539-43. https://doi.org/10.1097/SCS.0000000000003851

2. Horne RP, Meara DJ, Granite EL. Idiopathic bone cavities of the mandible: an update on recurrence rates and case report. Oral Surg Oral Med Oral Pathol Oral Radiol 2014;117:e71-3. https://doi. org/10.1016/j.oooo.2012.03.037

3. Chrcanovic BR, Gomez RS. Idiopathic bone cavity of the jaws: an updated analysis of the cases reported in the literature. Int J Oral Maxillofac Surg 2019;48:886-94. https://doi.org/10.1016/ j.ijom.2019.02.001

4. Perdigão PF, Silva EC, Sakurai E, Soares de Araújo N, Gomez RS. Idiopathic bone cavity: a clinical, radiographic, and histological study. Br J Oral Maxillofac Surg 2003;41:407-9. https://doi. org/10.1016/s0266-4356(03)00145-1

5. Battisti MPL, Soares MQS, Rubira CMF, Bullen IRFR, Lauris JRP, Damante JH. Assessment of spontaneous resolution of idiopathic bone cavity. J Appl Oral Sci 2018;26:e20170288. https://doi. org/10.1590/1678-7757-2017-0288
6. Discacciati ED, de Faria VM, Garcia NG, Sakai VT, Pereira AA, Hanemann JA. Idiopathic bone cavity: case series involving children and adolescents. J Investig Clin Dent 2012;3:103-8. https:// doi.org/10.1111/j.2041-1626.2011.0087.x

7. Harnet JC, Lombardi T, Klewansky P, Rieger J, Tempe MH, Clavert JM. Solitary bone cyst of the jaws: a review of the etiopathogenic hypotheses. J Oral Maxillofac Surg 2008;66:2345-8. https:// doi.org/10.1016/j.joms.2007.08.035

8. Assaf AT, Solaty M, Zrnc TA, Fuhrmann AW, Scheuer H, Heiland M, et al. Prevalence of Stafne's bone cavity--retrospective analysis of 14,005 panoramic views. In Vivo 2014;28:1159-64.

9. Velez I, Siegel MA, Mintz SM, Rolle R. The relationship between idiopathic bone cavity and orthodontic tooth movement: analysis of 44 cases. Dentomaxillofac Radiol 2010;39:162-6. https://doi. org/10.1259/dmfr/12528297

10. You MS, Kim DY, Ahn KM. Surgical management of idiopathic bone cavity: case series of consecutive 27 patients. J Korean Assoc Oral Maxillofac Surg 2017;43:94-9. https://doi.org/10.5125/jkaoms.2017.43.2.94

11. An SY, Lee JS, Benavides E, Aminlari A, McDonald NJ, Edwards PC, et al. Multiple simple bone cysts of the jaws: review of the literature and report of three cases. Oral Surg Oral Med Oral Pathol Oral Radiol 2014;117:e458-69. https://doi.org/10.1016/ j.oooo.2014.03.004

12. Cortell-Ballester I, Figueiredo R, Berini-Aytés L, Gay-Escoda C. Traumatic bone cyst: a retrospective study of 21 cases. Med Oral Patol Oral Cir Bucal 2009;14:E239-43.

13. Rushton MA. Solitary bone cysts in the mandible. Br Dent J 1946;81:37-49.

14. Tabrizi R, Karagah T, Shahidi S, Zare N. Does platelet-rich plasma enhance healing in the idiopathic bone cavity? A single-blind randomized clinical trial. Int J Oral Maxillofac Surg 2015;44:1175-80. https://doi.org/10.1016/j.ijom.2015.05.011

15. Manganaro AM. Review of the idiopathic bone cavity of the jaws. Mil Med 1997;162:734-6.

16. Roma LG, Lopes CB, Netto JNS, Miranda ÁMMA, Pires FR. Idiopathic bone cavity: clinicopathologic features from a case series with emphasis on differential diagnosis of chronic apical periodontitis. J Endod 2021;47:221-5. https://doi.org/10.1016/ j.joen.2020.11.004

17. Copete MA, Kawamata A, Langlais RP. Solitary bone cyst of the jaws: radiographic review of 44 cases. Oral Surg Oral Med Oral Pathol Oral Radiol Endod 1998;85:221-5. https://doi.org/10.1016/ s1079-2104(98)90430-9

18. Tong AC, Ng IO, Yan BS. Variations in clinical presentations of the simple bone cyst: report of cases. J Oral Maxillofac Surg 2003;61: 1487-91. https://doi.org/10.1016/j.joms.2003.05.003

19. Suei Y, Taguchi A, Tanimoto K. Simple bone cyst of the jaws: evaluation of treatment outcome by review of 132 cases. J Oral Maxillofac Surg 2007;65:918-23. https://doi.org/10.1016/ j.joms.2006.06.297

20. Resnick CM, Dentino KM, Garza R, Padwa BL. A management strategy for idiopathic bone cavities of the jaws. J Oral Maxillofac Surg 2016;74:1153-8. https://doi.org/10.1016/j.joms.2015.12.014

How to cite this article: Ryu J, Nam I, Shin SH, Kim YD, Lee JY. Idiopathic bone cavity: clinical and radiological features of 90 retrospective cases and surgical treatment. J Korean Assoc Oral Maxillofac Surg 2021;47:360-364. https://doi.org/10.5125/ jkaoms.2021.47.5.360 